Chapter 21

\title{
Conversion of Biomass to Bio-Oil in Sub- and Supercritical Water
}

\author{
Armando T. Quitain, Chan Yi Herng, Susana Yusup, \\ Mitsuru Sasaki and Yoshimitsu Uemura \\ Additional information is available at the end of the chapter
}

http://dx.doi.org/10.5772/59947

\section{Introduction}

Biomass-derived energy is widely considered to be the most potential and feasible among many forms of available energy on earth. Unlike any other renewable energy sources, such as geothermal, solar and wind which only generate heat and power, biomass can be converted to solid, liquid and gaseous fuels [1]. However, the choice of conversion methods suitable for a particular type of biomass and the target fuels becomes a challenge because of the complex three-dimensional (3D) structure connecting the main biomass components (i.e. lignin, cellulose and hemicellulose). This structure gives strength to the materials, and offers resistance that protects them against chemicals and microbial attack making it very difficult to hydrolyze. An effective dissociation of these components and their subsequent separation are needed for the production of high value products from lignocellulosic biomass [2]. One promising approach introduced recently is "hydrothermal liquefaction method" or commonly referred to as "hydrothermal upgrading" in many parts of Europe, wherein biomass is liquefied using water as a solvent at elevated temperatures and pressures.

\section{Hydrothermal liquefaction (or upgrading) of biomass}

Researches related to hydrothermal liquefaction of biomass have gained significant momentum during the last decade. Search for published literatures under the keywords "hydrothermal liquefaction" using SCOPUS database resulted into heavy turn outs of about 257 published articles in the recent 5 years as compared to only 40 articles during the previous 5 -year term. Several review articles of the method have also been published recently including the most 
comprehensive review of the technology summarized by Peterson et al. [3]. Reviews on its application to various biomass components such as protein, carbohydrates, lignin and fats have also been reported [4]. The most recent applications to the liquefaction of microalgae and marine biomass have also been summarized [5-8]. This hot-compressed water has also been compared with other hydrolysis methods [9] and shows it to be very attractive economically and environmentally because of higher sugar recovery even in the absence of acid and chemical catalysts.

The increasing popularity of this method is due to the deemed tremendous opportunities that biomass of any sources can offer as energy carrier, combined with the promising properties of water at high temperature and high pressure, especially under sub- and supercritical conditions.

\section{Water under sub- and supercritical conditions}

Water under sub- and supercritical conditions behaves totally different to that at ambient conditions, and its properties have been extensively reviewed by G. Brunner in his recent publication [10], which is basically based on the work by M. Modell in the 70s. To summarize, water with a dielectric constant of about 80 at ambient condition changes its properties in near critical (or subcritical) conditions, which can be used as a solvent for ionic or polar species. But, as the temperature approaches the critical temperature $\left(\mathrm{Tc}=373^{\circ} \mathrm{C}, \mathrm{Pc}=22.1 \mathrm{MPa}\right)$ and beyond (supercritical), the dielectric constant dramatically decreases to less than 10 (similar to that of methylene chloride) [11], behaving like a non-polar solvent that can dissolve and degrade a variety of non-polar organic compounds (please refer to Fig. 1 for the typical phase diagram of a substance).

Other than the dielectric constant, which indicates polarity, the ion product also exhibits changes in the properties of water. Water dissociates to produce hydrated hydrogen (hydronium ion) and hydroxyl ions. Under ambient conditions, the product of their concentrations is about $10-14(\mathrm{~mol} / \mathrm{L})^{2}$. The ion product also changes dramatically with increasing temperature, and the maximum product is obtained at a temperature of about $250^{\circ} \mathrm{C}$, under saturated vapor pressure. Having low dielectric constant and high ion product, water under near critical (subcritical) conditions become a suitable solvent for hydrolysis of organic compounds, even without any additives. With these properties, water serves as a potential solvent and a catalyst for organic reactions.

The review of G. Brunner [10] also showed several physicochemical properties of water under the above-mentioned conditions including density, viscosity and solubility of some gases and hydrocarbons. Sophisticated techniques for the measurement of those properties under high temperature and high pressure conditions were also presented. A micro-cell for potentiometric $\mathrm{pH}$ measurements of aqueous solutions in supercritical state has been reported [12]. An apparatus utilizing an optical cell under flow conditions was also developed to measure solubility, salt deposition and Raman spectroscopic studies in aqueous solutions near the critical point [13]. Mixing of solutions under supercritical water conditions had been a 


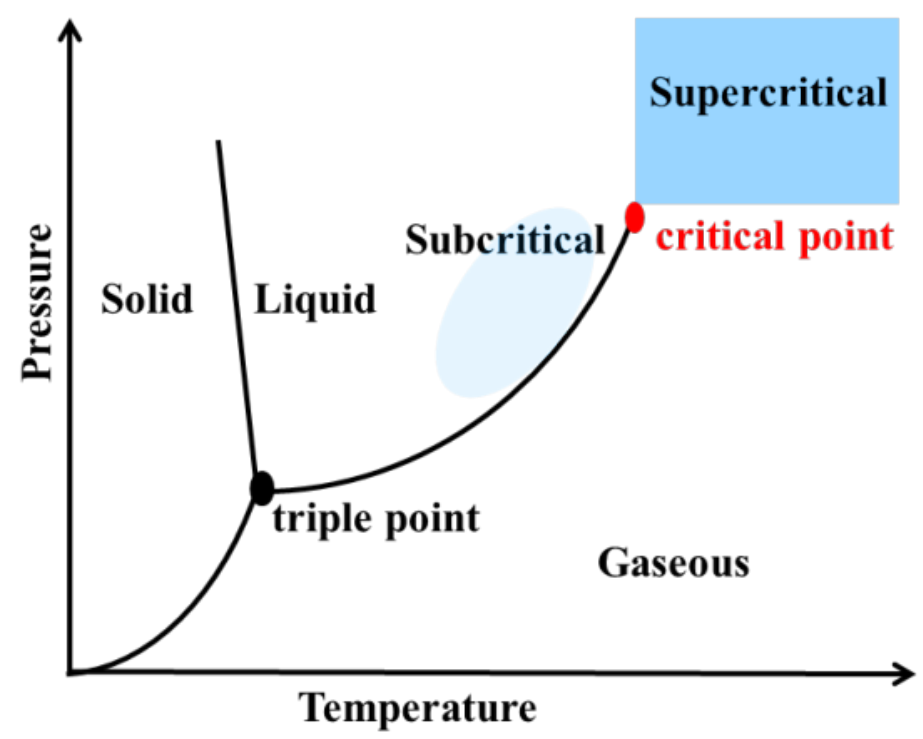

Figure 1. Typical phase diagram of any substance (for $\mathrm{H}_{2} \mathrm{O}: \mathrm{Tc}=373^{\circ} \mathrm{C}, \mathrm{Pc}=22.1 \mathrm{MPa}$ ).

\section{Properties of Sub and Supercritical Fluids}

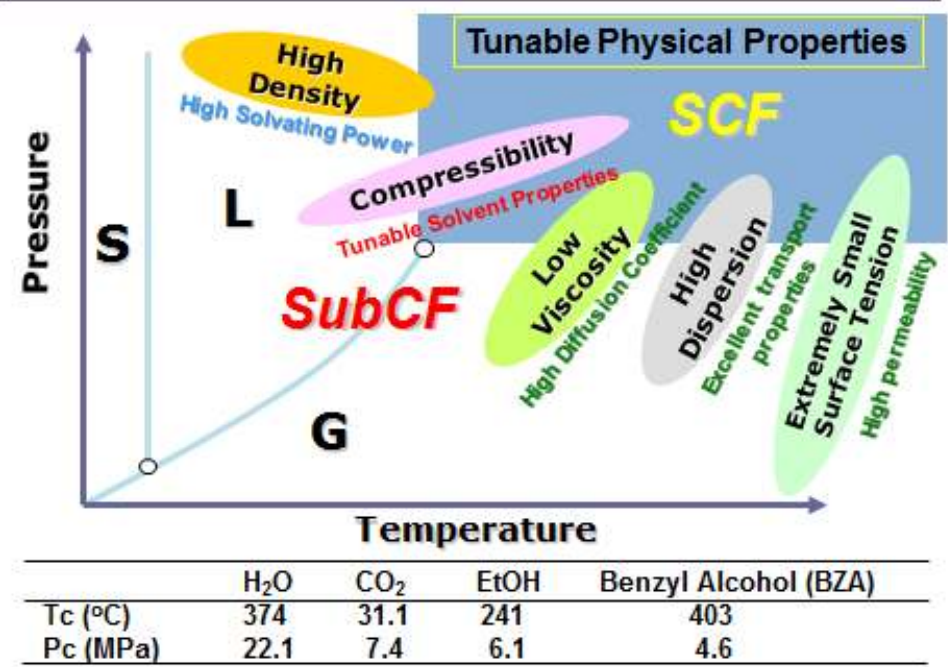

Figure 2. Summary of tunable physical properties of sub- and supercritical water and comparison of critical temperatures and pressures of some commonly used supercritical solvents. 
challenging and hot topic, a device for direct observation of channel-tee mixing has been developed for this purpose [14]. Further, a reactor for the studies of in-situ X-ray scattering studies of nanoparticle formation in supercritical water system was also developed [15]. The advantages of supercritical fluids with regard to its physicochemical properties are summarized in Fig. 2, including easily tunable physical properties which make the water suitable for highly selective extraction and reaction processes involving biomass samples.

\section{Potential biomass feedstocks}

Biomass being considered for bio-oil production includes woody biomass, grass and most recently different types of micro- and macroalgae. The characteristics of these feedstocks will be introduced here giving more emphasis on oil palm biomass which is selected as one of the main materials investigated in this work.

\subsection{Oil palm biomass}

Malaysia is one of many agricultural countries in the world, producing main agricultural crops such as oil palm, rubber, cocoa, rice and coconut [16]. Hence, the amount of production of agricultural wastes and residues is staggering with 47762 ktons of biomass generated as of year 2007. These biomass feedstocks have been long identified as a source of renewable energy which could reduce the dependency of fossil fuels as the main source of energy supply and multiple fine chemicals. The abundance of various biomass feedstocks has provided a good potential for their utilization. Thus, this has been extensively investigated more especially in looking for the best technology applicable for this conversion into either fuels or fine chemicals more efficiently, effectively and economically. Among the many available biomass feedstocks, those that are abundantly present in the Southeast Asian region are mostly derived from oil palm plantation.

Oil palm plantation in Malaysia is the most important agricultural crop, producing biomass close to about 37.0 million tons in 2008. This biomass consists of $22 \%$ empty fruit bunch (EFB), $13.5 \%$ fruit press fiber (FPF) and $5.5 \%$ shell. This high amount of oil palm biomass wastes could be utilized in the production of bio-oil, a promising future renewable energy source. In this research, the oil palm wastes such as empty fruit bunch (EFB), mesocarp fiber (MCF) and palm kernel shell (PKS) will be utilized as feedstocks for the hydrothermal liquefaction process to produce bio-oil using sub- and supercritical water technologies as depicted in Fig. 1. Fig. 3 shows images of the samples and the lignocellulosic composition with respect to the lignin, hemicellulose and cellulose contents. The EFB has lower lignin content at about $18 \%$. The PMF and PKS have almost similar composition consisting of about 30-33\% lignin, 22\% hemicellulose and $24 \%$ cellulose. These changes in composition could have significant effect on its liquefaction. Table 1 summarizes the ultimate analysis and high heating value (HHV) of the samples. The EFB has the lowest carbon content at $43.6 \%$, but has the highest oxygen content at $50.2 \%$. The HHV of EFB and PMF are almost the same at $16.3 \mathrm{MJ} / \mathrm{kg}$, while PKS has about $17.5 \mathrm{MJ} / \mathrm{kg}$ of heat value. 

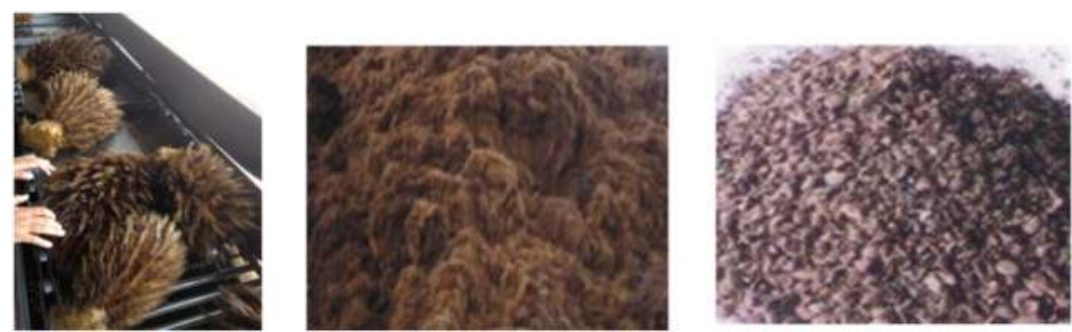

Empty fruit brunch (EFB) Palm mesocarp fiber (PMF) Palm kernel shell (PKS)

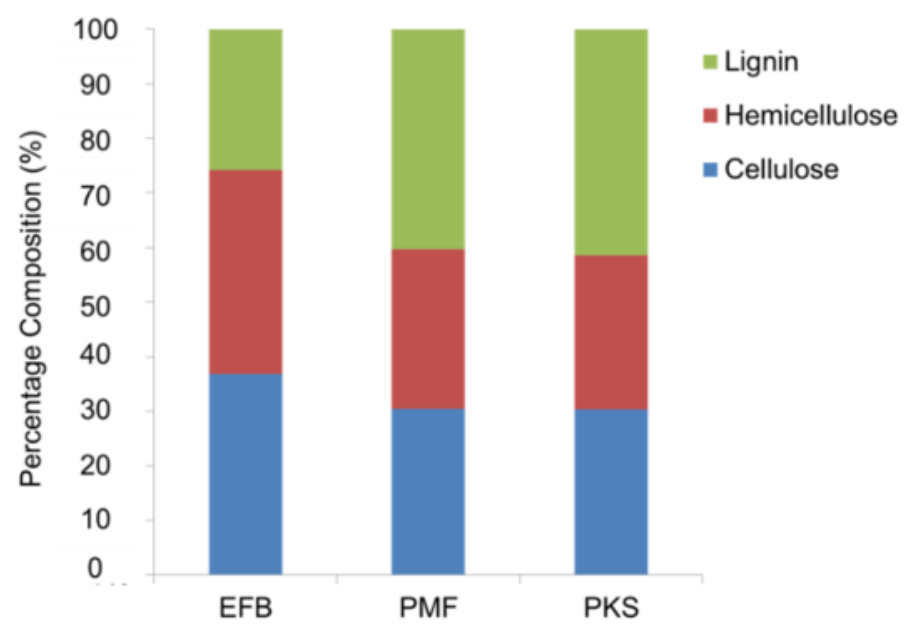

Figure 3. Lignocellulosic composition of Malaysian oil palm biomass samples.

\begin{tabular}{ccccc}
\hline Element & & EFB & PMF & PKS \\
\hline Carbon & $(\mathrm{C})(\%)$ & 43.6 & 46.3 & 47.8 \\
\hline Hydrogen & $(\mathrm{H})(\%)$ & 4.0 & 4.7 & 4.1 \\
\hline Nitrogen & $(\mathrm{N})(\%)$ & 2.0 & 1.4 & 0.5 \\
\hline Sulfur & $(\mathrm{S})(\%)$ & 0.2 & 0.2 & 0.2 \\
\hline $\begin{array}{c}\text { Oxygen } \\
\text { (by difference) }\end{array}$ & $(\mathrm{O})(\%)$ & 50.2 & 47.4 & \\
\hline $\begin{array}{c}\text { High Heating } \\
\text { Value (HHV) } \\
(\mathrm{MJ} / \mathrm{kg})\end{array}$ & 16.3 & 16.5 & 17.5 & \\
\hline
\end{tabular}

Table 1. Ultimate analysis and HHV of various Malaysian oil palm biomass samples 


\subsection{Algal biomass (microalgae or macroalgae)}

Algae are considered to be primitive plants lacking in roots, stems and leaves [17]. This inherent structure of these type of plants makes it very suitable for energy production [18]. Thus, its use as feedstocks for bio-oil production is gaining popularity in recent years due also to the presence of some functional components including oils, proteins and carbohydrates [8]. Among the various types of algae, microalgae are the most potential energy source because cultivation and production of these biofeedstocks do not match those for food production [5]. The concept of bio-oil conversion using these materials has been introduced in 1970s, but mainly focused on direct thermochemical method. Recently, liquefaction under hydrothermal condition has also received increasing attention because of the advantages the method can offer for rapid reaction, no pre-drying of samples and no restrictions due to lipid contents [8]. Hydrothermal liquefaction (HTL) converts biomass feedstocks into four phases including the biocrude oil (or simply referred to as bio-oil), aqueous products, solid residue and gaseous products.

\section{Objectives of the study}

This work focused on the conversion of biomass (mainly oil palm biomass) to bio-oil by liquefaction under hydrothermal conditions using sub- and supercritical water. The effects of operating parameters such as temperature and pressure on the liquefaction were studied. The obtained bio-oil was then characterized using various analytical methods such as TG-DTA and GC-MS analyses. Other approaches like the use of catalysts to enhance liquefaction rates and selectivity of the products, and coupling of microwave irradiation will also be introduced.

\section{Experimental methodology}

\subsection{Chemicals and reagents}

Most of the chemical reagents used in this study, such as toluene for separation of bio-oil from the solvent, were purchased from Wako Chemicals (Japan).

\subsection{Experimental methods}

The apparatus for hydrothermal experiments (AKICO Co. Japan) shown in Fig. 4 consists of a batch-type Inconel reactor (about $8.8 \mathrm{~cm}^{3}$ inner volume) and a heating electric furnace. Mechanical stirring of reactor is provided with a cyclic horizontal swing span of $2 \mathrm{~cm}$ fixed at a frequency of 60 cycles per minute. The amount of solvent used in each experiment depends on the desired reaction pressure. Only water was used as solvents for liquefaction experiments. Critical temperatures (Tc) and pressures $(\mathrm{Pc})$ for water are $\mathrm{Tc}=375^{\circ} \mathrm{C}, \mathrm{Pc}=22.1 \mathrm{MPa}$, respectively. It took about $15 \mathrm{~min}$ to reach the set reaction temperature of 210 to $300^{\circ} \mathrm{C}$. The reaction time was varied from 0.5 to $8 \mathrm{~h}$. After the reaction time elapsed, batch reactor was quenched 
in a water bath for rapid cooling. The degradation products were then separated for analyses. The degradation rate (DR) was then calculated from the amount of resin removed from the sample on the basis of the amount of resin originally present, and reported in $\%$.

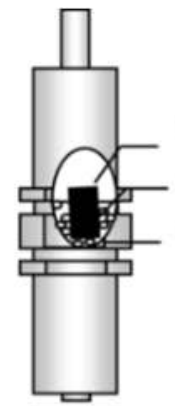

Reactor

SUS 316

Volume $8.8 \mathrm{ml}$

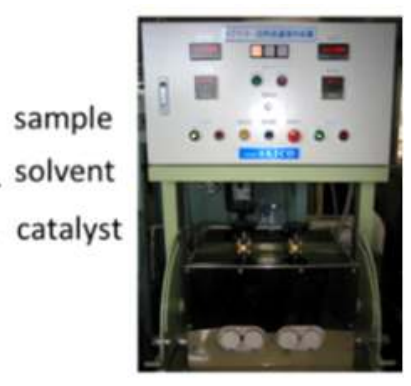

Electric furnace

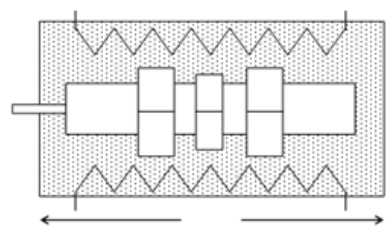

Schematic diagram of a batch reactor inside the electric furnace (arrows indicate cyclic horizontal movement for mixing of samples inside the reactor)

Figure 4. Schematic diagram of the reactor and actual apparatus for solvothermal experiments $\left(\operatorname{Tmax}=500^{\circ} \mathrm{C}\right.$, Pmax=50MPa).

Biomass samples were loaded into the reactor $(8.8 \mathrm{~mL})$ with distilled water at a sample to water ratio of 1:10. The reactor was inserted into the heating chamber preheated at the desired temperature, and then was allowed to react for $1 \mathrm{~h}$. After $1 \mathrm{~h}$ had elapsed, the heater was turned off and the reactor was quenched in water at room temperature. After sufficiently cooling the reactor, its content was washed and rinsed with water and toluene. The toluene solution was subjected under vacuum in a rotary evaporator set at $\mathrm{T}=60^{\circ} \mathrm{C}$ to remove toluene and obtained the bio-oil for further analyses.

\subsection{Gas Chromatography-Mass Spectrometry (GC-MS) analysis}

The obtained bio-oil was analyzed by gas chromatography-mass spectrometry (GC-MS, Hewlett Packard-6890 series, Palo Alto, CA), coupled with a mass selective detector (Hewlett Packard-5973). The GC conditions were as follows:

Oven Temperature: $40^{\circ} \mathrm{C}(3 \mathrm{~min}) \rightarrow 230^{\circ} \mathrm{C} \rightarrow 300^{\circ} \mathrm{C}(3 \mathrm{~min})$, rate $=5^{\circ} \mathrm{C} / \mathrm{min}$

Injector/Detector Temperature: $250^{\circ} \mathrm{C}$, Injection Volume: $0.5 \mu \mathrm{L}$

Carrier Gas: Helium (split ratio of 12: 1, flow rate of $24 \mathrm{~mL} \mathrm{~min}{ }^{-1}$ )

Ionizing energy: $70 \mathrm{eV}$

The compounds corresponding to the peaks appearing in the chromatograms resulting from the GC-MS analyses were identified by comparing the mass spectra of each peak with those stored in the database (the NIST library). 


\subsection{Thermogravimetry-Differential Thermal Analysis (TG-DTA) analysis}

To determine the temperature-dependent mass behavior of biomass, thermogravimetrydifferential thermal analysis (TG-DTA) was performed using EXSTAR 6000 TG/DTA6300 apparatus (Seiko Instruments. Inc., Japan). The temperature range investigated was from 35 to $500^{\circ} \mathrm{C}$ at a heating rate of $20^{\circ} \mathrm{C} / \mathrm{min}$ under $\mathrm{N}_{2}$ gas flow.

\section{Results and discussion}

\subsection{Effect of temperature and pressure}

Table 2 summarizes the effect of temperature and pressure on sub- and supercritical hydrothermal liquefaction of oil palm biomass at reaction time of $1 \mathrm{~h}$ and sample-to-water ratio $=1$ : 10. From all the runs, the bio-oil yields of PMF were higher than that of EFB. This can be explained by the differences in composition of cellulose, hemicellulose and lignin of the biomass samples. PMF has relatively higher lignocellulosic content (75.9\%) and lignin content $(30.6 \%)$ compared to $\operatorname{EFB}(72.1 \%$ and 18.6 , respectively).

At 25 and $30 \mathrm{MPa}$, the yield of bio-oil decreased with increasing temperature, most likely due to possible secondary decomposition of biomass components at higher temperatures, causing gasification and charring. At $35 \mathrm{MPa}$, increasing the temperature from $360^{\circ} \mathrm{C}$ to $390^{\circ} \mathrm{C}$ resulted into an increase in bio-oil yield. However, increasing the temperature further to $450^{\circ} \mathrm{C}$ decreased the yield. High pressure increases water density, hence enhancing solubility of the materials and its decomposition. However, higher temperature causes secondary decomposition of biomass and recombination of some free radicals, leading to gas and char formation.

\begin{tabular}{|c|c|c|c|c|c|}
\hline \multirow{2}{*}{ Reaction Conditions } & \multirow{2}{*}{$\mathrm{T}\left({ }^{\circ} \mathrm{C}\right)$} & \multirow{2}{*}{$\mathrm{P}(\mathrm{MPa})$} & \multicolumn{3}{|c|}{ Bio-oil Yield (wt\%) } \\
\hline & & & EFB & PMF & PKS \\
\hline \multirow{6}{*}{ Subcritical water } & 330 & 25 & $15.72 \pm 1.05$ & $16.40 \pm 0.21$ & $22.83 \pm 0.56$ \\
\hline & 330 & 30 & $16.96 \pm 1.18$ & $15.72 \pm 0.81$ & $25.62 \pm 1.87$ \\
\hline & 330 & 35 & $15.68 \pm 0.68$ & $14.79 \pm 0.21$ & $23.67 \pm 0.27$ \\
\hline & 360 & 25 & $25.31 \pm 0.44$ & $22.71 \pm 0.83$ & $26.55 \pm 1.29$ \\
\hline & 360 & 30 & $26.02 \pm 0.44$ & $23.22 \pm 0.54$ & $27.54 \pm 0.70$ \\
\hline & 360 & 35 & $22.76 \pm 0.28$ & $21.75 \pm 0.01$ & $23.44 \pm 1.24$ \\
\hline \multirow{3}{*}{ Supercritical water } & 390 & 25 & $37.39 \pm 0.67$ & $34.32 \pm 1.87$ & $38.53 \pm 1.46$ \\
\hline & 390 & 30 & $28.17 \pm 0.35$ & $27.57 \pm 1.03$ & $31.16 \pm 0.81$ \\
\hline & 390 & 35 & $30.16 \pm 0.98$ & $24.07 \pm 1.04$ & $29.35 \pm 0.71$ \\
\hline
\end{tabular}

Table 2. Effect of temperature and pressure on sub- and supercritical hydrothermal liquefaction of oil palm biomass (reaction time $=1 \mathrm{~h}$, sample-to-water ratio $=1: 10$ ) 
The increase in pressure has changing impacts on the bio-oil yield. Increasing the pressure increases the water density and also the solubility of the target compounds. These properties combined with inherent highly diffusive characteristics of supercritical fluids can enhance the ability of water to penetrate more easily into the sample matrix, hence improving extraction and decomposition of target compounds in biomass.

However, in some cases the increase in solvent density due to increase in pressure could result into cage effect for the $\mathrm{C}-\mathrm{C}$ bonds present in the molecules of the target biomass components. This in effect inhibits the cleavage of C-C bonds, thus lowering hydrolysis rate resulting into low yields of liquefied products. Hence, as observed from the obtained data in this study, variation of pressure may or may not have positive results in sub- and supercritical hydrothermal liquefaction of oil palm biomass. This observation merits more detailed investigation in the future.

\subsection{Relation of obtained results with the lignocellulosic composition of samples}

As shown in the results of TG-DTA analysis of the samples in Fig. 5 and Fig. 6, respectively, hemicellulose degrades at a lower temperature range of $210-330^{\circ} \mathrm{C}$ due to the less uniform structure and low-degree crystallinity. Cellulose is a naturally occurring polymer consisting of linearly linked monomer units of glucose; hence, it has a higher degree of crystallinity and degrades at $300-375^{\circ} \mathrm{C}$. Lignin is a highly crossed-linked polyphenolic aromatic polymer having no ordered repeating units. As such, lignin has the highest thermal stability and decomposed at $150-1000^{\circ} \mathrm{C}$.

Due to higher lignin content, higher temperature and pressure $\left(450^{\circ} \mathrm{C}\right.$ and $\left.30 \mathrm{MPa}\right)$ are needed to degrade PMF and PKS compared to that of EFB $\left(390^{\circ} \mathrm{C}\right.$ and $\left.25 \mathrm{MPa}\right)$. PKS produces highest bio-oil yield at optimum condition, followed by PMF and EFB due to decreasing lignin content in the order of PKS > PMF > EFB.

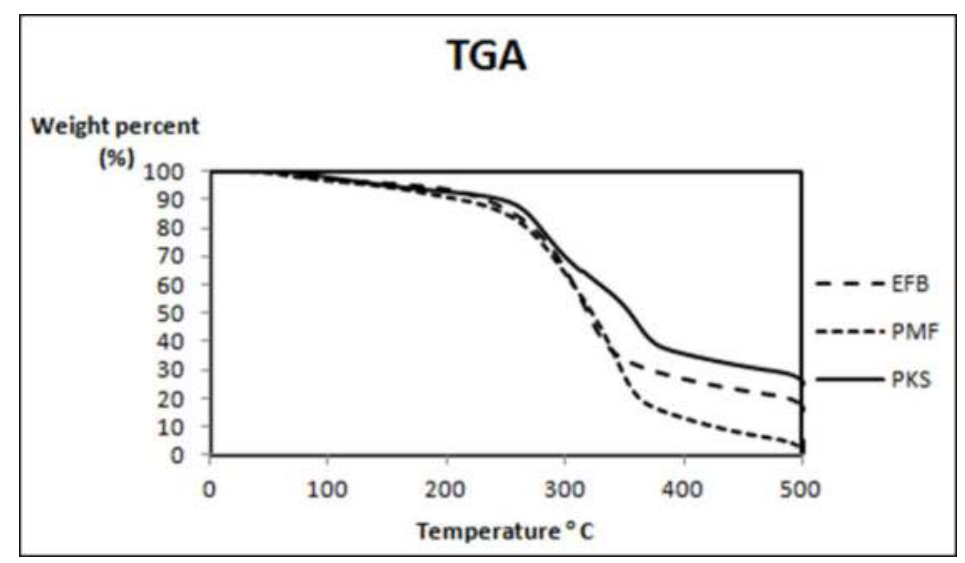

Figure 5. Results of thermogravimetric analysis of various oil palm biomass samples. 


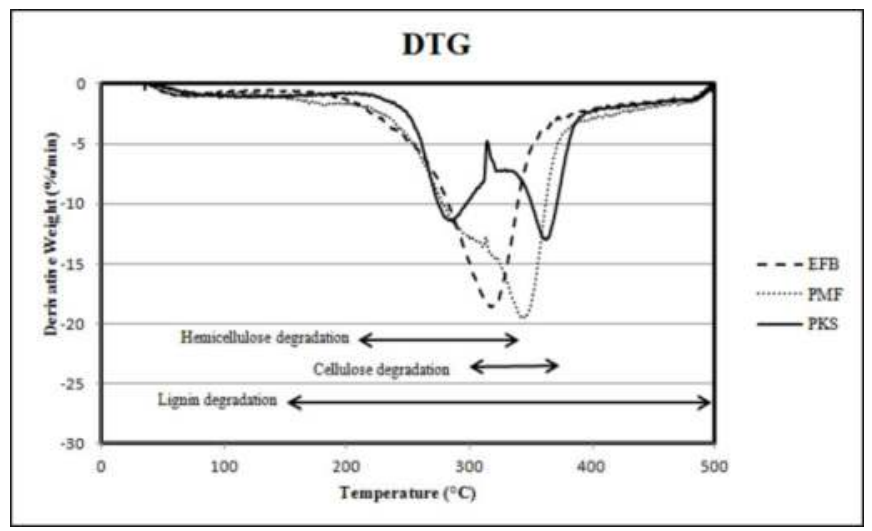

Figure 6. Results of thermogravimetric analysis of various oil palm biomass samples.

\subsection{Results of GC-MS analyses of the obtained bio-oils}

The typical GC-MS chromatograms of the bio-oil obtained from EFB, PMF and PKS at the optimum condition in this study $\left(\mathrm{T}=390^{\circ} \mathrm{C}, \mathrm{P}=25 \mathrm{MPa}\right)$ are shown in Fig. 7. The bio-oil obtained was typically dark brown, highly viscous liquid with distinct smoky odor. The chromatograms were almost identical, consisting of mostly phenolic and benzene compounds as depicted in Table 3. These compounds were likely obtained mainly from decomposition of lignin and cellulosic components of the biomass. Slight differences in composition for PKS as compared to other samples were observed as can be seen in the appearances of peaks 12 to 16 . These peaks were identified as phenolic (peak 12), 1,2,3-trimethoxybenzene (peak 13), ester compound (peak 14), ketone (peak 15) and 1-(2,5-dimethoxyphenyl)-propanol (peak 16). These results agree with chemical compositions reported in literature consisting of several hundreds of organic compounds, such as acids, alcohols, aldehydes, esters, ketones, phenols and ligninderived oligomers [19]. It is also possible that some of these products are undesirable; thus, post-treatment of the obtained biocrude oil by removal of these unwanted compounds or by upgrading has been suggested. Production of these unwanted molecules can also be avoided by using catalysts suitable for selective degradation of the lignocellulosic components into the target compounds in addition to the enhancement of liquefaction rates.

\begin{tabular}{llllll}
\hline \multirow{2}{*}{$\begin{array}{l}\text { Peak No. } \\
\text { Retention } \\
\text { Time (min) }\end{array}$} & Compound & \multicolumn{3}{l}{ Percentage Peak Area (\%) } \\
\cline { 5 - 6 } & 18.44 & Ethylbenzene & EFB & PMF & PKS \\
\hline 1 & 18.77 & Benzene, 1,3-dimethyl- & 5.12 & 5.30 & 3.93 \\
3 & 20.03 & 2-cyclopenten-1-one, 2-methyl & 5.55 & - & - \\
4 & 22.38 & Phenol & 3.42 & - & 32.30
\end{tabular}




\begin{tabular}{|c|c|c|c|c|c|}
\hline \multirow{2}{*}{ Peak No. } & \multirow{2}{*}{$\begin{array}{l}\text { Retention } \\
\text { Time (min) }\end{array}$} & \multirow{2}{*}{ Compound } & \multicolumn{3}{|c|}{ Percentage Peak Area (\%) } \\
\hline & & & EFB & PMF & PKS \\
\hline 5 & 24.93 & 2,3-dimethylcyclopent-2-en-1-one & 13.04 & 5.28 & 3.08 \\
\hline 6 & 25.20 & Phenol, 2-methyl- & - & - & 2.26 \\
\hline 7 & 26.72 & Mequinol / Phenol, 2-methoxy & 11.14 & 16.28 & 16.13 \\
\hline 8 & 30.08 & Phenol, 2-methoxy-4-methyl & - & 4.11 & 4.40 \\
\hline 9 & 32.69 & 1,2-benzenediol, 4-methyl- & 11.97 & - & - \\
\hline 10 & 32.70 & Phenol, 4-ethyl-2-methoxy & - & 9.64 & 8.78 \\
\hline 11 & 34.73 & Phenol, 2,6-dimethoxy & 10.80 & 17.66 & 14.66 \\
\hline 12 & 35.26 & $\begin{array}{l}\text { Phenol, 2-methoxy-4-[[[2-(4- } \\
\text { hydroxyphenyl)ethyl]ami }\end{array}$ & - & - & 2.17 \\
\hline 13 & 37.28 & 1,2,3-trimethoxybenzene & - & - & 2.50 \\
\hline 14 & 39.08 & Dodecanoic acid, methyl ester & - & - & 3.30 \\
\hline 15 & 39.30 & $\begin{array}{l}\text { Ethanone,1-(2,6-dihydroxy-4- } \\
\text { methoxyphenyl)- }\end{array}$ & - & - & 3.69 \\
\hline 16 & 41.40 & 1-(2,5-dimethoxyphenyl)-propanol & - & - & 2.80 \\
\hline
\end{tabular}

Table 3. Major chemical components of the obtained bio-oil identified using GC-MS and NIST library

\section{Use of catalysts to enhance liquefaction rates}

The use of catalysts is indispensable and important to enhancement of liquefaction rates of biomass even under hydrothermal conditions. This will shorten reaction time even under mild conditions, thus reducing the required energy and processing cost. Some of the catalysts used for this purpose includes both homogeneous (alkali, alkali salts, etc.) and heterogeneous catalysts (metal oxides, etc.).

Akhtar et al. [20] has investigated liquefaction of empty palm fruit bunch (EPFB) under subcritical water conditions using various alkalis (such as $\mathrm{NaOH}, \mathrm{KOH}$ and $\mathrm{K}_{2} \mathrm{CO}_{3}$ ). Catalytic performance and biomass to water ratio suitable for high EPFB conversion, liquid hydrocarbons yield and lignin degradations were screened in a batch reactor operating at $270^{\circ} \mathrm{C}$ and 2 $\mathrm{MPa}$ in a reaction time of $20 \mathrm{~min}$. Results showed that addition of alkali had positive effect on conversion, liquefaction and lignin degradation, increasing the rates by almost two-folds compared to that without any catalysts. The reactivity of the alkalis was in the order of $\mathrm{K}_{2} \mathrm{CO}_{3}>\mathrm{KOH}>\mathrm{NaOH}$. The composition of bio-oil also depended on the type of catalysts, obtaining the highest yield of phenols using $\mathrm{K}_{2} \mathrm{CO}_{3}(1.0 \mathrm{M})$, while much of ester compounds were obtained using $1.0 \mathrm{M} \mathrm{NaOH}$. 

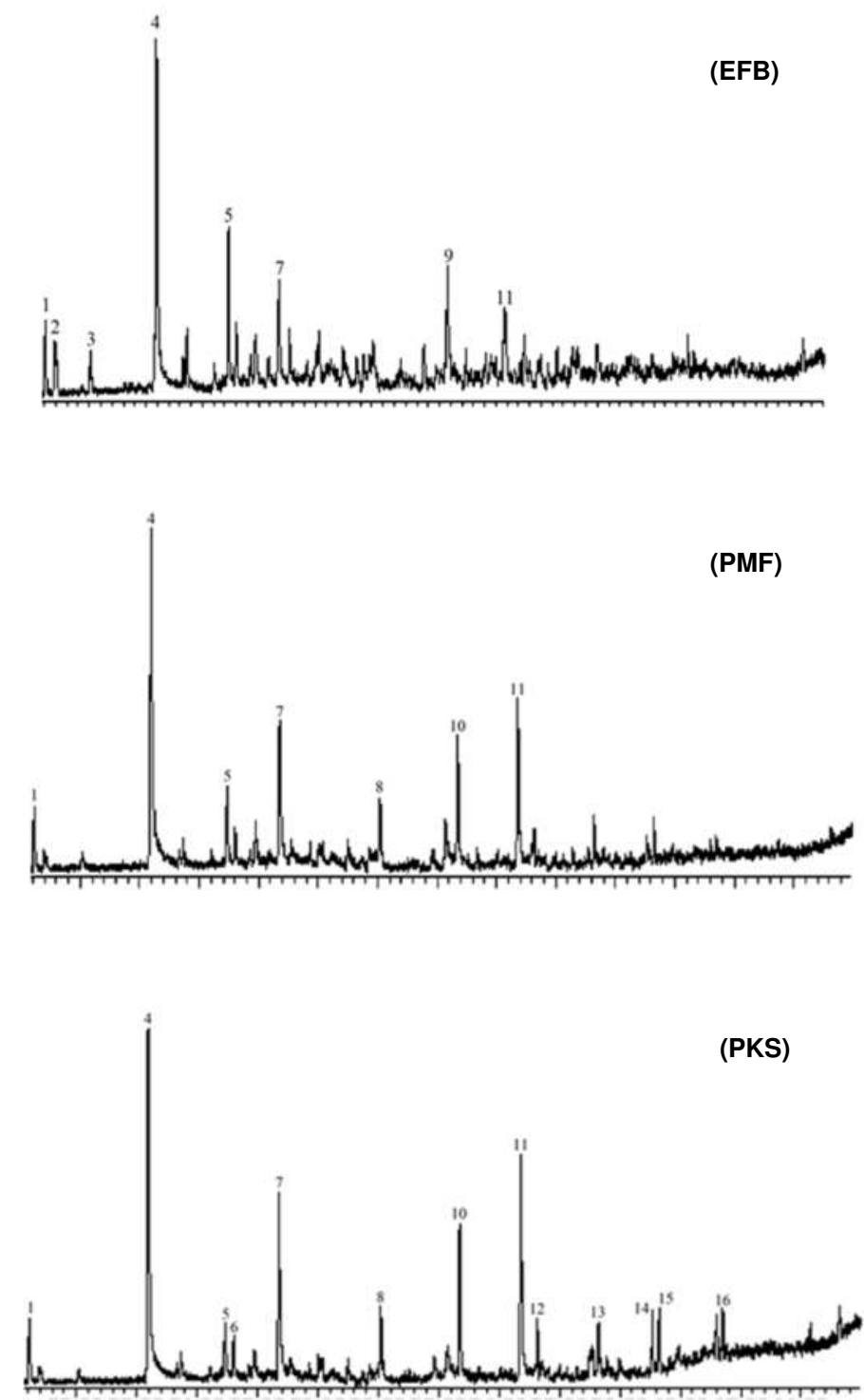

Figure 7. Typical GC-MS chromatograms of bio-oil obtained from EFB, PMF and PKS at the optimum condition $(\mathrm{T}=$ $390^{\circ} \mathrm{C}, \mathrm{P}=25 \mathrm{MPa}$ ).

Various catalytic processes for production of biofuels from palm oil and oil palm biomass were also summarized by Chew and Bhatia [21]. This includes reviews on catalytic processes of palm oil to produce biodiesel, and cracking to produce high-grade biofuels. This review also discusses biomass gasification to produce hydrogen and syngas, and its conversion to liquid 
fuels by Fischer-Tropsch synthesis (FTS), including upgrading of liquid/gas fuels obtained from liquefaction/pyrolysis of biomass. Several catalysts including zeolites such as ZSM- 5 and aluminosilicates were reported to enhance biomass conversion and upgrading; however, application to hydrothermal liquefaction was not reported.

The use of rare earth modified zeolite, Ce/HZSM-5 has been proposed by $\mathrm{Xu}$ et al. [22] for hydrothermal liquefaction of microalgae. They found that this novel type of catalysts exhibited good potential and benefits for the preparation of bio-oil from microalgae (e.g. Chlorella pyrenoidosa) with high efficiency.

Several other catalysts have been screened for hydrothermal catalytic processing of pretreated algal oil that was produced from the hydrothermal liquefaction of Chlorella pyrenoidosa [23]. The activities of $5 \% \mathrm{Pt} / \mathrm{C}, 5 \% \mathrm{Pd} / \mathrm{C}, 5 \% \mathrm{Ru} / \mathrm{C}, 5 \% \mathrm{Pt} / \mathrm{C}$ (sulfided), $\mathrm{Mo}_{2} \mathrm{C}, \mathrm{MoS}_{2}$, alumina, $\mathrm{CoMo} /$ $\gamma-\mathrm{Al}_{2} \mathrm{O}_{3}$ (sulfided), $\mathrm{Ni} / \mathrm{SiO}_{2}-\mathrm{Al}_{2} \mathrm{O}_{3}, \mathrm{HZSM}-5$, activated carbon, and Raney-Ni for hydrothermal hydrodeoxygenation and hydrodenitrogenation of the pretreated algal oil at $400^{\circ} \mathrm{C}$ were investigated. It was reported that $\mathrm{Ru} / \mathrm{C}$ showed the best performance for deoxygenation, and Raney-Ni was the most suitable catalyst for denitrogenation. The upgraded oil from the $\mathrm{Ru} / \mathrm{C}$ catalyzed reaction contained the highest hydrocarbon content, the highest fraction of material boiling below $400^{\circ} \mathrm{C}$, and the highest higher heating value $(45.1 \mathrm{MJ} / \mathrm{kg}$ ). All of the metal catalysts produced freely flowing upgraded oil. The combination of $\mathrm{Ru} / \mathrm{C}$ and Raney $\mathrm{Ni}$, which showed very good deoxygenation and denitrogenation of the oil, produced upgraded oil that retained $86 \%$ of the heating value in the original pretreated oil. This upgraded oil was also produced in a higher yield (77.2 wt.\%) and with lower gas (9.4 wt.\%), coke (15.6 wt.\%) and water-soluble products yields $(2.1 \mathrm{wt} . \%)$ than from either catalyst alone. The authors also suggested a two-step biocrude treatment strategy (non-catalytic treatment followed by catalytic upgrading) and a two-component catalyst bed in the second step for the hydrothermal catalytic upgrading of algal biocrude.

\section{Coupling with microwave irradiation}

Microwave technology utilizes electromagnetic waves for heating as a result of friction produced by oscillation of molecules as they realign with microwave upon absorption. Microwaves operate in between infrared radiation and radiofrequencies of $30 \mathrm{GHz}$ to $300 \mathrm{MHz}$, corresponding to wavelengths of $1 \mathrm{~cm}$ to $1 \mathrm{~m}$. Strict government regulations only allow domestic and microwave apparatus to operate at either $122.2 \mathrm{~cm}(2.45 \mathrm{GHz})$ or $33.3 \mathrm{~cm}(900$ $\mathrm{MHz}$ ) to avoid interference with RADAR transmissions and telecommunications [24].

Using microwave, rapid heating occurs as a result of heat being generated within the material, unlike the conventional method where heating of material is performed by conduction from heat sources outside of the vessel. Many microwave-assisted reactions are accelerated due to this rapid internal heating, resulting to tremendous increase in reaction rates compared to the conventional methods. Thus, even at shorter reaction times, higher yields and selectivity of target compounds are expected. Some other reactions not possible with the conventional heating methods had also been reported to proceed by microwave irradiation. Kingston and 
Haswell had summarized available information related to the fundamentals of microwave chemistry in sample preparations and other applications [25].

Microwave non-thermal effects on reaction have also been reported to occur, thus even at milder conditions, dramatic increase in the yield can be obtained. Hoz et al. reported in a review of related topics some evidences and postulates on the existence of this phenomenon, but doubts still remain for many researchers [26]. Jacob et al. has reported some interesting results on specific microwave effects on thermal and non-thermal interaction of microwaves with materials [27]. Some of the topics discussed include "hot spots" or localized heating, molecular agitation, improved transport properties of materials with microwaves, and some evidences on reaction rate enhancements as result of these improved properties of materials. A lot of mechanisms of activation of materials are thought to be possible with microwave interaction; thus, it is difficult to simply treat microwave heating as similar to that of the conventional.

The above-mentioned thermal and non-thermal effects of microwave irradiation offer enormous benefits to the treatment of biomass for synthesis of biofuels including energy efficiency, development of a compact process, rapid heating and instant on-off process (instant heatingcooling process), among many other possible advantages.

Microwave-based pretreatment approach utilizes both thermal and non-thermal effects generated by an extensive intermolecular collision as a result of realignment of polar molecules with microwave oscillations. Compared to conventional heating, electromagnetic field generated by microwave has the ability to directly interact with the material to produce heat, thereby accelerating chemical, physical and biological processes. The advantages of employing microwave rather than the conventional heating include reduction of process energy requirements, selective processing and capability for instantaneous starting and ceasing of the process. This also offers enormous benefits such as energy efficiency due to rapid and selective heating, and the possibility for developing a compact process.

When microwave is applied to the treatment of lignocellulosic biomass, the unique feature of selectively heating the more polar part will result in an improved disruption of the recalcitrant structures of lignocellulose. With the non-thermal effects, electromagnetic field enhances the destruction of crystalline structures and changes the super molecular structure of lignocellulosic material thereby improving its reactivity.

Microwave pretreatment is also an energy-efficient and environmentally benign technology that aids in the transport of chemicals into the substrates. The project team from the US Department of Energy in partnerships with research institutes including the Oak Ridge National Laboratory [28] has showed that by opening the cellular microstructures of wood, for example, microwave pretreatment could permit pumping chemicals for easy access of even large sections $(10 \mathrm{~cm}$ long $\times 10 \mathrm{~cm}$ diameter) of hardwoods. The project team has demonstrated that, for both hardwood and softwood chips, microwave pretreatment can decrease both $\mathrm{H}$ factor and chemicals required to pulp hardwoods and softwoods by greater than $40 \%$ with acceptable quality. The steam pressure generated inside the wood breaks the pit membranes and vessel cell walls, thereby enhancing the woods permeability to chemicals and process liquors. 
Other than the lignocellulosic biomass, the use of microwave for pretreatment of samples for a more efficient oil extraction and pretreatment of free fatty acids for biodiesel conversion has also been proposed.

\section{Summary and future directions}

This research focuses on the feasibility of converting oil palm biomass wastes to bio-oil under sub- and supercritical water. The effects of reaction temperature and pressure on the efficiency of the liquefaction of EFB, MCF and PKS were investigated. Based on the obtained results, the optimum liquefaction condition for EFB, PMF and PKS could be obtained at supercritical conditions of water. EFB gave the highest bio-oil yield at $390^{\circ} \mathrm{C}$ and $25 \mathrm{MPa}$, whereas for PMF and PKS, the highest bio-oil yields were at $450^{\circ} \mathrm{C}$ and $30 \mathrm{MPa}$. Lignocellulosic contents of the biomass affect their optimum liquefaction condition and the yield of bio-oil. Temperature and pressure have also different impacts on the bio-oil yield. Compared to pyrolysis, the proposed hydrothermal liquefaction method using sub- and supercritical fluid utilizes the water originally present in the feedstock, thus avoiding the energy-intensive drying procedures.

Future directions will cover evaluation of global kinetics of the liquefaction rate based on the reaction equilibrium data collected and use of various catalysts to enhance liquefaction rates. The major contribution expected from this research will be a new technology as applied to the liquefaction of biomass using sub- and supercritical fluid.

\section{Acknowledgements}

This work was partly supported by JSPS Bilateral Exchange Program - Open Partnership Joint Research Projects with UTP (Malaysia). YUTP Research Grant for CYH stay in Kumamoto University to carry out the experimental works is also being acknowledged.

\section{Author details}

Armando T. Quitain ${ }^{1 *}$, Chan Yi Herng ${ }^{2}$, Susana Yusup ${ }^{2}$, Mitsuru Sasaki ${ }^{3}$ and Yoshimitsu Uemura ${ }^{4}$

*Address all correspondence to: quitain@kumamoto-u.ac.jp

1 Graduate School of Science and Technology, Kumamoto University, Japan

2 Chemical Engineering Department, Universiti Teknologi PETRONAS, Malaysia

3 Institute of Pulsed Power Science, Kumamoto University, Japan

4 Centre for Biofuel and Biochemical Research, Universiti Teknologi PETRONAS, Malaysia 


\section{References}

[1] Nilsen MH, Antonakou E, Bouzga A, Lappas A, Mathisen K, Stocker M. Investigation of the effect of metal sites in the Me-Al-MCM-41 (Me = Fe, $\mathrm{Cu}$ or $\mathrm{Zn})$ on the catalytic behavior during the pyrolysis of wooden based biomass. Microporous and Mesoporous Materials 2007; 105, 189-203.

[2] Hamzeh Y, Ashori A, Khorasani Z, Abdulkani A, Abyaz A. Pre-extraction of hemicelluloses from bagasse fibers: Effects of dry-strength additives on paper. Industrial Crops and Products 2013; 43(5), 365-371.

[3] Peterson AA, Vogel F, Lachance RP, Fröling M, Antal MJ Jr., Tester JW. Thermochemical biofuel production in hydrothermal media: A review of sub- and supercritical water technologies. Energy \& Environmental Science 2008; 1, 32-65.

[4] Toor SS, Rosendahl L, Rudolf A. Hydrothermal liquefaction of biomass: A review of subcritical water technologies. Energy 2011;36, 2328-2342.

[5] Barreiro DL, Prins W, Ronsse F, Brilman W. Hydrothermal liquefaction (HTL) of microalgae for biofuel production: State of the art review and future prospects. Biomass and Bioenergy 2013; 53, 113-127.

[6] Brennan L, Owende P. Biofuels from microalgae - A review of technologies for production, processing, and extractions of biofuels and co-products. Renewable and Sustainable Energy Reviews 2010; 14, 557-577.

[7] Ruiz HA, Rodriguez-Jasso RM, Fernandes BD, Vicente AA, Teixeira JA. Hydrothermal processing, as an alternative for upgrading agriculture residues and marine biomass according to the biorefinery concept: A review. Renewable and Sustainable Energy Reviews 2013; 21, 35-51.

[8] Tian C, Li B, Liu Z, Zhang Y, Lu H. Hydrothermal liquefaction for algal biorefinery: A critical review. Renewable and Sustainable Energy Reviews 2014; 38, 933-950.

[9] Yu Y, Lou X, Wu H. Some recent advances in hydrolysis of biomass in hot-compressed water and its comparisons with other hydrolysis methods. Energy and Fuels $2008 ; 22,46-60$.

[10] Brunner G. Near critical and supercritical water. Part I. Hydrolytic and hydrothermal processes. Journal of Supercritical Fluids 2009; 47, 373-381.

[11] Haar LJ, Gallagher S, Kell GS. National Bureau of Standards/National Research Council steam tables. Hemisphere Publishing Corp, Bristol, PA (1984)

[12] Sue K, Ouchi F, Arai K. Microcell for potentiometric $\mathrm{pH}$ measurements of supercritical aqueous solutions. Journal of Supercritical Fluids 2006; 39, 271-276.

[13] Hurst WS, Hodes MS, Bowers WJ Jr., Bean VE, Maslar JE, Griffith P, Smith KA. Optical flow cell and apparatus for solubility, salt deposition and Raman spectroscopic 
studies in aqueous solutions near the water critical point. Journal of Supercritical Fluids $2001 ; 22,157-166$.

[14] Aizawa T, Masuda Y, Minami K, Kanakubo M, Nanjo H, Smith RL. Direct observation of channel-tee mixing of high-temperature and high-pressure water. Journal of Supercritical Fluids 2007; 43, 222-227.

[15] Bremholm M, Jensen H, Brummerstedt Iversen S, Brummerstedt Iversen B. Reactor design for in situ X-ray scattering studies of nanoparticle formation in super-critical water syntheses. Journal of Supercritical Fluids 2008; 44, 385-390.

[16] Sumathi S, Chai SP, Mohamed AR. Utilization of oil palm as a source of renewable energy in Malaysia. Renewable and Sustainable Energy Reviews 2008; 12, 2404-2421.

[17] Lee RE. Phycology. Cambridge University Press, New York (1980).

[18] Khan SA, Rashmi, Hussain MZ, Prasad S, Banerjee UC. Prospects of biodiesel production from microalgae in India. Renewable and Sustainable Energy Reviews 2009; 13 (9), 2361-2372.

[19] Xiu S, Shahbazi A. Bio-oil production and upgrading research: A review. Renewable and Sustainable Energy Reviews 2012; 16, 4406-4414.

[20] Akhtar J, Kuang SK, Amin NS. Liquefaction of empty palm fruit bunch (EPFB) in alkaline hot compressed water. Renewable Energy 2010; 35 (6), 1220-1227.

[21] Chew TL, Bhatia S. Catalytic processes towards the production of biofuels in a palm oil and oil palm biomass-based biorefinery. Bioresource Technology 2008; 99 (17), 7911-7922.

[22] Xu Y, Zheng X, Yu H, Hu X. Hydrothermal liquefaction of Chlorella pyrenoidosa for bio-oil production over Ce/HZSM-5. Bioresource Technology 2014; 156, 1-5.

[23] Bai X, Duan P, Xu Y, Zhang A, Savage PE. Hydrothermal catalytic processing of pretreated algal oil: A catalyst screening study. Fuel 2014; 120, 141-149.

[24] Mingos DMP, Baghurst DR. Applications of microwave dielectric heating effects to synthetic problems in chemistry, In: Microwave-Enhanced Chemistry, H. M. (Skip) Kingston \& S. J. Haswell, (Ed.), pp. 3-50. American Chemical Society, Washington, DC, ISBN 0-8412-3375-6 (1997).

[25] Kingston HM (Skip), Haswell SJ. Microwave-enhanced chemistry: fundamentals, sample preparation and applications. American Chemical Society, Washington, DC, ISBN 0-8412-3375-6 (1996).

[26] De la Hoz A, Diaz-Ortiz A, Moreno A. Critical review: Microwaves in organic synthesis. thermal and non-thermal microwave effects. Chemical Society Reviews 2005; 34, 164-178. 
[27] Jacob J, Chia LHL, Boey FYC. Review: Thermal and non-thermal interaction of microwave irradiation with materials. Journal of Material Science 1995; 30, 5321-5327.

[28] Compere A, Parent D, et al. Increasing yield and quality of low-temperature, low-alkali kraft cooks with microwave pre-treatment. US Department of Energy, Energy Efficiency and Renewable Energy Reports (2007). 